\title{
High-resolution genomic microarrays for X-linked mental retardation
}

Dorien Lugtenberg, MSc, Joris A. Veltman, PhD, and Hans van Bokhoven, PhD

\begin{abstract}
Developments in genomic microarray technology have revolutionized the study of human genomic copy number variation. This has significantly affected many areas in human genetics, including the field of X-linked mental retardation (XLMR). Chromosome X-specific bacterial artificial chromosomes microarrays have been developed to specifically test this chromosome with a resolution of approximately 100 kilobases. Application of these microarrays in X-linked mental retardation studies has resulted in the identification of novel X-linked mental retardation genes, copy number variation at known X-linked mental retardation genes, and copy number variations harboring as yet unidentified $X$-linked mental retardation genes. Further enhancements in genomic microarray analysis will soon allow the reliable analysis of all copy number variations throughout this chromosome at the kilobase or single exon resolution. In this review, we describe the developments in this field and specifically highlight the impact of these microarray studies in the field of X-linked mental retardation. Genet Med 2007:9(9):560-565.
\end{abstract}

Key Words: mental retardation, array CGH, XLMR, chromosome X, genomic microarrays, copy number variation, CNV

\section{X-LINKED MENTAL RETARDATION}

The human brain is a highly complex structure, and its normal development and functioning is critically dependent on the proper and tightly regulated activity of a large number of genes. Indeed, approximately $80 \%$ of all genes are expressed above background levels in the adult mouse brain. ${ }^{1}$ Consequently, there are more than 1000 Mendelian disorders listed in OMIM for which mental retardation (MR) is one or the only hallmark of the condition. Hundreds of causative genes have already been identified, ${ }^{2}$ but this is only the tip of the iceberg, as most patients remain undiagnosed.

MR has a prevalence of $1 \%$ to $3 \%$ in the general population $^{3,4}$ and is one of the main reasons for referral to the clinical genetics department, because a genetic defect is calculated to account for approximately $50 \%$ of cases. When MR is the only clinical feature, the condition is referred to as nonspecific; if the MR is accompanied by specific other features, the condition is referred to as specific. Until now, the focus of MR research has mainly been on isolated patients with specific clinically recognizable MR syndromes and on familial cases of

\footnotetext{
From the Department of Human Genetics, Radboud University Nijmegen Medical Centre, Nijmegen, The Netherlands.

Joris A. Veltman, PhD, Department of Human Genetics-855, Radboud University Nijmegen Medical Centre, P.O. Box 9101, 6500 HB Nijmegen, The Netherlands; E-mail: j.veltman@antrg.umcn.nl

Disclosure: The authors report no conflict of interest.

A supplementary table is available via the ArticlePlus feature at www.geneticsinmedicine.org. Please go to the September issue and click on the ArticlePlus link posted with the article in the Table of Contents to view this material.
}

Submitted for publication May 4, 2007.

Accepted for publication June 20, 2007.

DOI: 10.1097/GIM.0b013e318149e647 nonspecific MR caused by alterations on the $\mathrm{X}$ chromosome. There are several reasons for the initial interest of investigators and clinicians for X-linked mental retardation (XLMR). First, there is a $30 \%$ to $40 \%$ excess of male versus female patients with MR, suggesting an overrepresentation of $\mathrm{X}$ chromosomal defects causing MR. ${ }^{3-6}$ Second, X-linked inheritance can be easily recognized in small families with only two affected male patients and an obligate female carrier, for instance nephew and uncle. Finally, because of the hemizygous status of males, gene identification is sometimes easier than for autosomal conditions. For example, microdeletions in contiguous gene disorders have facilitated the positional cloning of a number of XLMR genes. ${ }^{7-9}$ The focus on XLMR has had consequences for the identification, especially of nonspecific MR genes. Some 25 genes that are involved in nonsyndromic MR have been identified on the $\mathrm{X}$ chromosome, whereas only three nonspecific autosomal MR genes have been resolved ${ }^{10-12}$ (http://xlmr. interfree.it/home.htm). In general, these genes are thought to cause problems in neuronal network formation in the brain, such as an inappropriate number of connections, incorrect connections, or synaptic plasticity defects. ${ }^{13-15}$

The XLMR genes identified until now account for the MR in approximately half of the families in which the genetic defect was previously mapped to the $\mathrm{X}$ chromosome. ${ }^{16}$ This success has been achieved essentially by two strategies: positional cloning and candidate gene analysis. The candidate gene approach is becoming increasingly important because of the power of high-throughput sequence analysis. ${ }^{16,17}$ Positional cloning approaches have been responsible for many of the initial successes. For example, the FACL4 (ACS4) gene was identified on the characterization of partial deletions across the region for the contiguous gene deletion syndrome consisting of Alport syndrome, elliptocytosis, and MR. ${ }^{9}$ Several other cytogeneti- 
cally visible deletions and duplications have eventually led to the identification of a causative gene in XLMR.7,8,18 In addition, a large number of $\mathrm{X}$ chromosomal deletions and duplications have been associated to a MR syndrome. In most cases, the large size of these aberrations precludes the identification of the single causative gene. In fact, it is likely that for many of these, the phenotype is caused by the abnormal dosage of a number of genes. The frequent involvement of X chromosomal aberrations in syndromic forms of XLMR suggests that submicroscopic deletions and duplications may be causative for other types of syndromic and nonsyndromic XLMR. Therefore, array-based comparative genomic hybridization protocols have been developed and applied to screen for copy number changes in mentally retarded male patients. In this review, we provide an update of the various approaches and the results obtained with them, including the identification of causative and polymorphic copy number changes and the identification of causative gene deletions and duplications.

\section{ARRAY-BASED COMPARATIVE GENOMIC HYBRIDIZATION}

Chromosome banding by karyotyping has only a limited resolution of 5 to $10 \mathrm{Mb}$ and requires dividing cells, usually peripheral blood leukocytes, for analysis. The fluorescence in situ hybridization (FISH) technology, however, is not suitable for unbiased genome-wide application, because a single hybridization experiment screens only for a limited number of genomic targets. The advantages of both technologies have recently been combined to enhance the genome-wide resolving power from the megabase to the kilobase level. Tools that have mediated these developments include (1) the generation of genome-wide clone resources integrated into the finished human genome sequence, (2) the development of high-throughput microarray platforms, and (3) the optimization of comparative genomic hybridization (CGH) protocols and data analysis systems. Together, these developments have accumulated in a socalled "molecular karyotyping" technology called array-based CGH (array CGH). Array CGH allows for sensitive and specific detection of single copy number changes of submicroscopic chromosomal regions throughout the entire human genome or specifically targeting a single chromosome, chromosome $\mathrm{X}$ in our case.

Initially, the microarrays used for genomic copy number profiling consisted of collections of PCR-amplified large-insert clones such as bacterial artificial chromosomes (BACs). Widely used clone sets cover the genome with either one clone per megabase (3,000 clones genome-wide, ${ }^{19,20} 150$ for chromosome X) or with complete tiling coverage of all unique genomic sequences $(32,000$ clones genome-wide, of which 1,500 map to chromosome $\mathrm{X}^{21,22}$ ). For XLMR studies, the subset of clones mapping to chromosome $\mathrm{X}$ have been selected and spotted on dedicated microarrays, which have the advantage that multiple replicates can be spotted and data analysis can be tailored toward the identification of subtle copy number variations $(\mathrm{CNV})$ at this specific chromosome. ${ }^{23-25}$ Validation of these tiling resolution chromosome X BAC microarrays using DNA samples from patients with known chromosome $\mathrm{X}$ alterations demonstrated that these microarrays are very useful in the identification of cryptic CNVs. In addition, these studies showed that the boundaries of genomic alterations could be clearly established with high resolution, thereby greatly facilitating genotype-phenotype studies.

A limitation of these in-house manufactured BAC microarrays, consisting of large-insert genomic clones, is that aberrations below $100 \mathrm{~kb}$ cannot be detected because of the size of the genomic fragments used as array elements. In addition, the production of microarrays containing more than a hundred thousand targets is not practically achievable for academic groups, especially because most available microarray spotters have a practical limitation of approximately 60,000 spots per slide. The latest generation of genomic microarrays is therefore developed by private enterprises. Many companies are now offering microarrays for genome-wide copy number profiling. These microarrays encompass oligonucleotides targeting random genomic sequences ${ }^{26,27}$ or single nucleotide polymorphisms (SNPs). ${ }^{28-30}$ The advantages of using such commercial platforms are numerous, as (1) they provide a higher genome coverage than most microarrays generated in academia (up to half a million oligonucleotides on a single microarray), (2) they can be produced in large quantities according to industrial quality standards,(3) they are available to all research and diagnostic laboratories, also those without dedicated microarray facilities, and(4) their widespread use generates large data sets of normal controls and patients with various disorders, which allows for highly sensitive analysis of potential genotypephenotype consequences. As an example, it is now possible to buy commercial microarrays covering the 155 megabases of chromosome $\mathrm{X}$ with a maximum of 385,000 oligonucleotides, resulting in a median probe spacing of one oligonucleotide every 340 basepairs (compared with one BAC every $100 \mathrm{~kb}$ on the tiling resolution microarrays). Alternatively, one can choose to analyze all coding exons of all chromosome $\mathrm{X}$ genes by developing a custom array targeting these approximately 800 genes at a very high density. Both novel approaches will soon allow the unbiased analysis of all CNVs on chromosome $\mathrm{X}$ in a single hybridization experiment.

\section{COPY NUMBER DETECTION ON THE X CHROMOSOME: AN OVERVIEW}

The incidence of causative genomic imbalances (both deletions and duplications) detectable by genome-wide tiling BAC-array resolution array CGH is approximately $10 \%$ in patients with unexplained MR, depending on the stringency of the clinical criteria that are used to select patients for testing. ${ }^{22,31,32}$ Similarly, a first chromosome X-specific array CGH study using tiling resolution BAC arrays identified causative CNVs in 3 of 40 patients with nonspecific XLMR, ${ }^{33} \mathrm{dem}$ onstrating the usefulness of this approach in the field of XLMR. This has been further exemplified by the recent identification of a novel nonspecific XLMR gene by this approach. ${ }^{34}$ In this study, we used array CGH to screen a boy with mental retardation, short stature, and retinal dystrophy for deletions and duplications on the $\mathrm{X}$ chromosome. A 1-Mb deletion in the Xp11.3 region was identified, including five genes: ZNF673, ZNF674, CHST7, SLC9A6 and RP2. The retinal dystrophy is 


\section{Lugtenberg et al.}

probably caused by the disruption of the RP2 gene, which left us with four novel candidate genes for mental retardation. Sequence analysis of these four genes in XLMR families with a linkage interval including Xp11.3 resulted in the detection of a nonsense mutation in one family in the KRAB-containing zinc finger gene ZNF674. Mutation analysis of this gene in 300 XLMR families without a linkage interval revealed two additional missense mutations in two families. The ZNF674 gene is part of a zinc finger gene cluster in which two other zinc finger genes are known to be involved in XLMR: ZNF41 and ZNF81. ${ }^{35,36}$ These data establish that there is a third KRAB/ZFP gene in this gene cluster that is involved in the development and/or maintenance of the human brain.

Chromosome X-specific array CGH studies have also uncovered deletions and duplications of chromosomal segments that included known XLMR genes not known to vary in their copy number. The most frequently found aberration of this kind so far is the duplication of a genomic region comprising the MECP2 gene in a number of XLMR families. ${ }^{33,37}$ Overlapping duplications and mouse studies indicate that the increased MECP2 levels

A
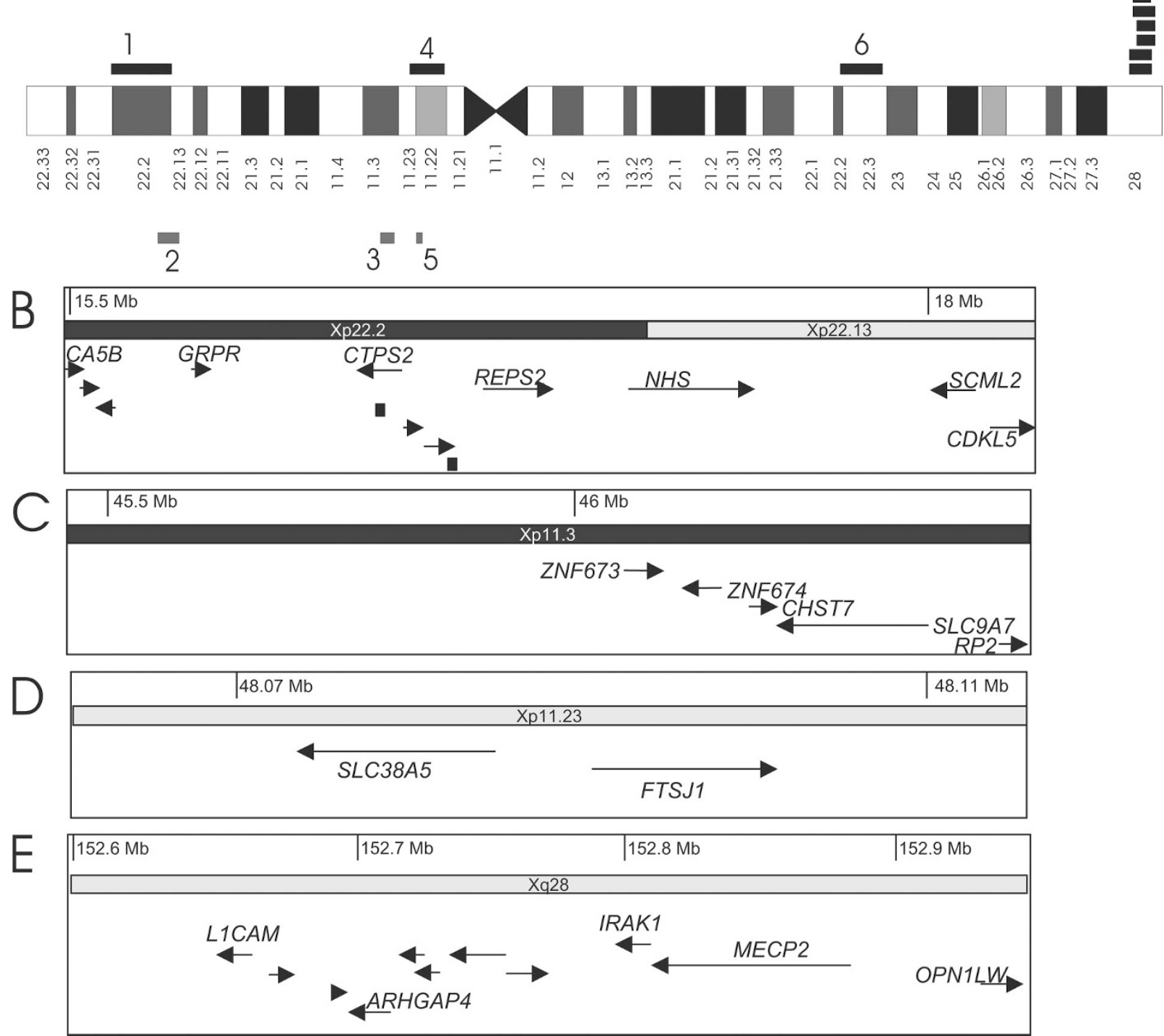

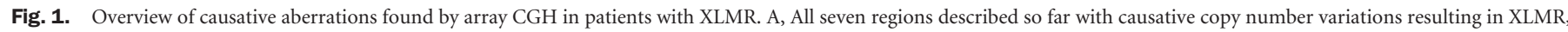

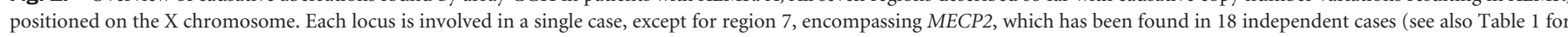

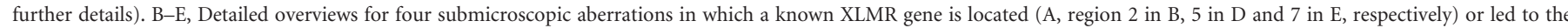
identification of a novel XLMR gene (A, region 3 in $\mathrm{C}$ ). 
Table 1

Size and position of causative $\mathrm{X}$ chromosomal copy number variations involved in XLMR

\begin{tabular}{lccccc}
\hline & & $\begin{array}{c}\text { Start } \\
(\mathrm{Mb})^{a}\end{array}$ & $\begin{array}{c}\text { End } \\
(\mathrm{Mb})^{a}\end{array}$ & $\begin{array}{c}\text { Size } \\
(\mathrm{Mb})\end{array}$ & Reference \\
\hline 1 & Gain & 9.7 & 16.4 & 6.7 & 33 \\
2 & Loss & 15.6 & 18.3 & 2.8 & 43 \\
3 & Loss & 45.2 & 46.5 & 1.3 & 34 \\
4 & Gain & 47.7 & 52.9 & 5.2 & 44 \\
5 & Loss & 48.19 & 48.23 & 0.05 & 42 \\
6 & Gain & 103.2 & 107.6 & 4.4 & 47 \\
7 & Gain & 152.8 & 153.2 & $0.4^{b}$ & $33,37,39,40$ \\
\hline
\end{tabular}

${ }^{a}$ Based on NCBI build 35 of the UCSC Genome Browser hg17 (http:// genome.ucsc.edu/).

${ }^{b}$ Critical duplicated region including MECP2 and IRAK1.

are causative for the severe neurological problems in male patients with a duplication of the region. ${ }^{38-41}$ Furthermore, a deletion including the FTSJ1 and SLC38A5 genes has been identified, as has a deletion including the CDKL5 and NHS genes. ${ }^{42,43}$

A third group of aberrations identified by array CGH comprises those in which many genes are involved and together account for the clinical observations in the patient. Often it is not possible to identify a single causative gene. For the X chromosome, several of these have been discovered. ${ }^{33,44-49}$ The collection of multiple cases of these multigenic alterations may prove to be essential for further gene identification studies. An overview of all causative submicroscopic CNVs detected by array CGH studies on the $\mathrm{X}$ chromosome in XLMR patients is presented in Figure 1 and Table 1.

Finally, array CGH studies have identified a large number of chromosomal CNVs in unaffected individuals, similar to findings in other regions in the human genome. ${ }^{33,45,46,50-55}$ These CNVs reflect normal genomic variation in the human population, which may still be clinically important individually or in various combinations as risk factors. There are eight published studies in which the array technology is used to screen for copy number changes along the $\mathrm{X}$ chromosome in control individuals. ${ }^{46,51-56}$ From these studies, as collected in the database of genomic variances (http://projects.tcag.ca), a total of $113 \mathrm{CNV}$ loci on the X chromosome can be identified (Fig. 2, plus supplementary data).

\section{DETAILED FOLLOW-UP STUDIES BY OTHER HIGH-THROUGHPUT TECHNOLOGIES}

The use of array technologies has provoked a rapid development of techniques to confirm the array data. For instance,

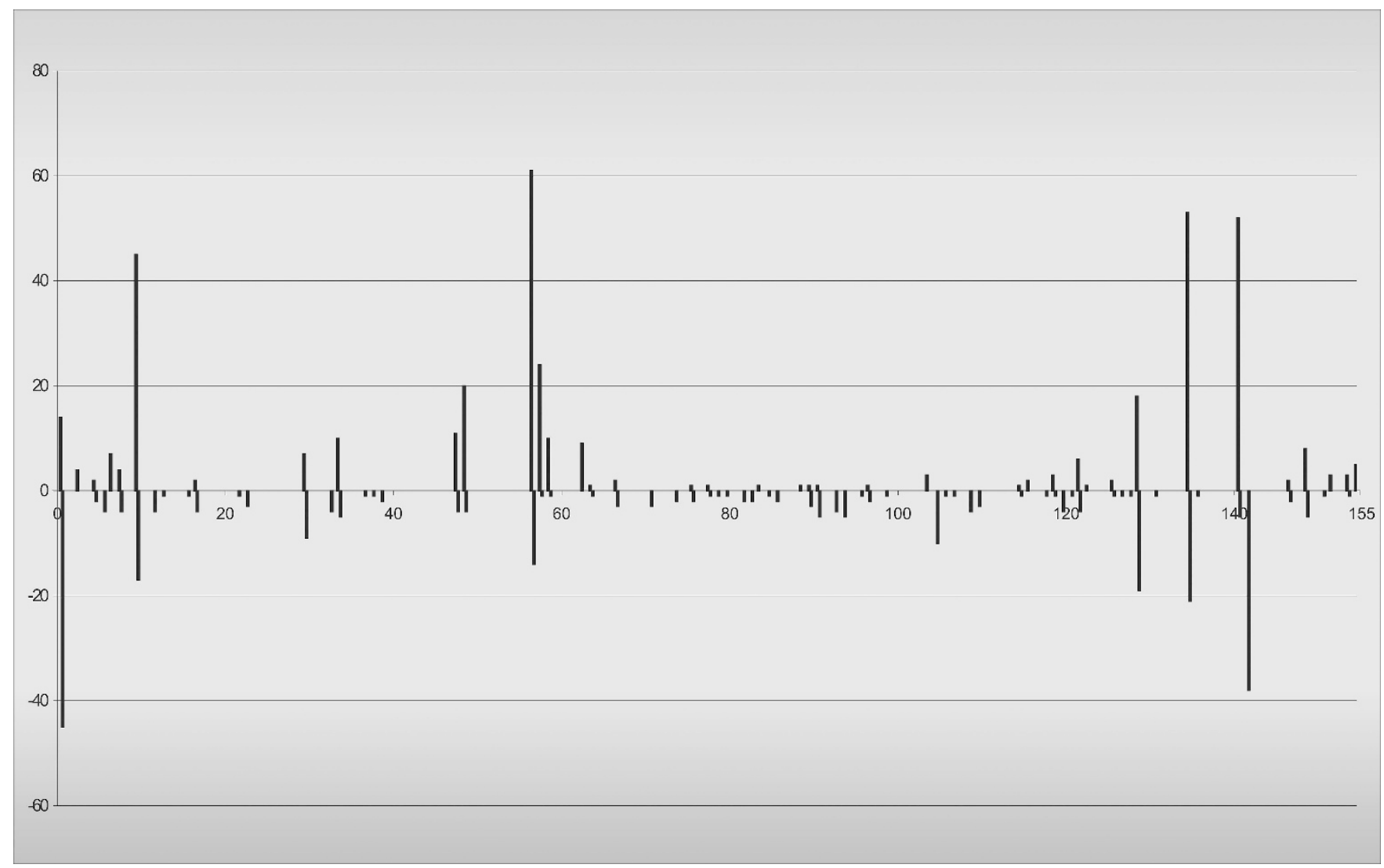

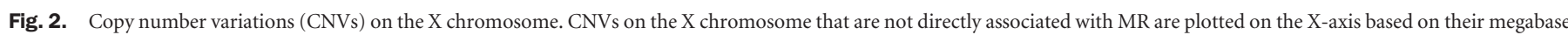

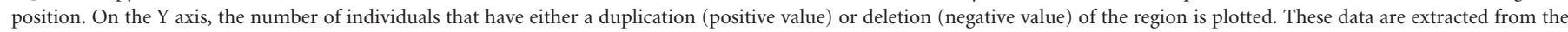

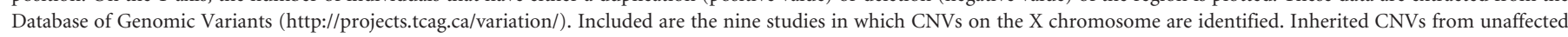

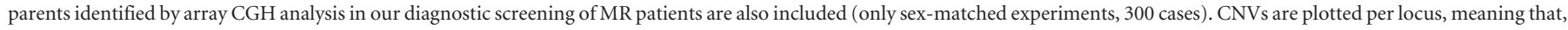
in some cases, more than one genomic position is combined to one data point. 
multiplex ligation-dependent probe amplification (MLPA) technology has rapidly developed to be a fast and easy method to confirm deletions and especially duplications identified by array CGH. ${ }^{57}$ The detection of recurrent deletions and duplications resulted in the development of standard tests to be used in a diagnostic setting. Several PCR-based kits, such as MLPA, cover regions in the genome that are known for causative deletions and duplications in patients with MR. An example is the $\mathrm{Xq} 28$ region, including the $M E C P 2$ gene. Array CGH studies established that duplications of the entire MECP2 gene cause severe neurological problems in male patients. MLPA has been instrumental either to screen for these duplications or to verify and fine map the duplications found by array CGH. ${ }^{39,40}$ One drawback of comparative technologies like array CGH or PCR assays, like MLPA in the case of genomic duplications, is that these do not allow for a genomic localization of the additional DNA sequence. Therefore, FISH-based approaches are often also used in the analysis of predisposing balanced rearrangements in parental DNA.

\section{CONCLUSION}

Genomic microarray technology has revolutionized the way we can study the human genome for the presence of copy number variation. This has significantly affected many areas in human genetics in recent years, including the field of XLMR. Chromosome X-specific BAC arrays have been developed in the last 3 years to specifically test this chromosome with the highest resolution possible, and this has contributed to identifying novel XLMR genes, identifying copy number variation at known XLMR genes, recognizing novel specific XLMR conditions, and describing novel cryptic copy number variations harboring as yet unidentified XLMR genes. Further enhancements in genomic microarray analysis will soon allow the reliable analysis of all copy number variations throughout this chromosome at the kilobase or single exon resolution. This will undoubtedly result in the identification of many additional causative CNVs and thereby further enhance our understanding of the genetics underlying this frequent disorder.

\section{ACKNOWLEDGMENTS}

This work was supported by grants from EU, QLG3-CT2002-01810 (to DL and HvB, EURO-MRX), and the Netherlands Organization for Health Research and Development (to JAV, ZonMW 912-04-047 and 917-66-363).

\section{References}

1. Lein ES, Hawrylycz MJ, Ao N, Ayres M. Genome-wide atlas of gene expression in the adult mouse brain. Nature 2007;445:168-176.

2. Inlow JK, Restifo LL. Molecular and comparative genetics of mental retardation. Genetics 2004;166:835-881.

3. Leonard H, Wen X. The epidemiology of mental retardation: challenges and opportunities in the new millennium. Ment Retard Dev Disabil Res Rev 2002;8:117-134.

4. Roeleveld N, Zielhuis GA, Gabreëls F. The prevalence of mental retardation: a critical review of recent literature. Dev Med Child Neurol 1997;39:125-132.
5. Rauch A, Hoyer J, Guth S, Zweier C, et al. Diagnostic yield of various genetic approaches in patients with unexplained developmental delay or mental retardation. Am J Med Genet A 2006;140:2063-2074.

6. Yeargin-Allsopp M, Murphy CC, Cordero JF, Decoufle P, et al. Reported biomedical causes and associated medical conditions for mental retardation among 10-year-old children, metropolitan Atlanta, 1985 to 1987. Dev Med Child Neurol 1997;39:142_149.

7. Berger W, Meindl A, van de Pol TJ, Cremers FP, et al. Isolation of a candidate gene for Norrie disease by positional cloning. Nat Genet 1992;1:199-203.

8. Carrié A, Jun L, Bienvenu T, Vinet M-C, et al. A new member of the IL-1 receptor family highly expressed in hippocampus and involved in X-linked mental retardation. Nat Genet 1999;23:25-31.

9. Meloni I, Muscoletta M, Raynaud M, Longo I, et al. FACL4, encoding fatty acid-CoA ligase 4, is mutated in nonspecific X-linked mental retardation. Nat Genet 2002;30: 436-440.

10. Basel-Vanagaite L, Attia R, Yahav M, Ferland RJ, et al. The CC2D1A, a member of a new gene family with $\mathrm{C} 2$ domains, is involved in autosomal recessive non-syndromic mental retardation. J Med Genet 2006;43:203-210.

11. Higgins JJ, Pucilowska J, Lombardi RQ, Rooney JP. A mutation in a novel ATPdependent Lon protease gene in a kindred with mild mental retardation. Neurology 2004;63:1927-1931.

12. Molinari F, Rio M, Meskenaite V, Encha-Razavi F, et al. Truncating neurotrypsin mutation in autosomal recessive nonsyndromic mental retardation. Science 2002; 298:1779-1781.

13. Ramakers GJA. Rho proteins and the cellular mechanisms of mental retardation. Am J Med Genet 2000;94:367-371.

14. Ropers HH, Hamel BC. X-linked mental retardation. Nat Rev Genet 2005;6:46-57.

15. Laumonnier F, Cuthbert PC, Grant SG. The role of neuronal complexes in human X-linked brain diseases. Am J Hum Genet 2007;80:205-220.

16. de Brouwer AP, Yntema HG, Kleefstra T, Lugtenberg D, et al. Mutation frequencies of X-linked mental retardation genes in families from the EuroMRX consortium. Hum Mutat 2007;28:207-208.

17. Tarpey PS, Raymond FL, O’Meara S, Edkins S, et al. Mutations in CUL4B, which encodes a ubiquitin E3 ligase subunit, cause an X-linked mental retardation syndrome associated with aggressive outbursts, seizures, relative macrocephaly, central obesity, hypogonadism, pes cavus, and tremor. Am J Hum Genet 2007;80:345-352.

18. Inoue K, Osaka H, Sugiyama N, Kawanishi C, et al. A duplicated PLP gene causing Pelizaeus-Merzbacher disease detected by comparative multiplex PCR. Am J Hum Genet 1996;59:32-39.

19. Fiegler H, Carr P, Douglas EJ, Burford DC, et al. DNA microarrays for comparative genomic hybridization based on DOP-PCR amplification of BAC and PAC clones. Genes Chromosomes Cancer 2003;36:361-374.

20. Vissers LE, de Vries BB, Osoegawa K, Janssen IM, et al. Array-based comparative genomic hybridization for the genomewide detection of submicroscopic chromosomal abnormalities. Am J Hum Genet 2003;73:1261-1270.

21. Ishkanian AS, Malloff CA, Watson SK, DeLeeuw RJ, et al. A tiling resolution DNA microarray with complete coverage of the human genome. Nat Genet 2004;36:299303.

22. de Vries BB, Pfundt R, Leisink M, Koolen DA. Diagnostic genome profiling in mental retardation. Am J Hum Genet 2005;77:606-616.

23. Veltman JA, Yntema HG, Lugtenberg D, Arts H, et al. High resolution profiling of X chromosomal aberrations by array comparative genomic hybridization. J Med Genet 2004;41:425-432.

24. Bauters M, Van Esch H, Marynen P, Froyen G. X chromosome array-CGH for the identification of novel X-linked mental retardation genes. Eur J Med Genet 2005;48: 263-275.

25. Hayashi S, Honda S, Minaguchi M, Makita Y, et al. Construction of a high-density and high-resolution human chromosome $\mathrm{X}$ array for comparative genomic hybridization analysis. J Hum Genet 2007;52:397-405.

26. Barrett MT, Scheffer A, Ben-Dor A, Sampas N, et al. Comparative genomic hybridization using oligonucleotide microarrays and total genomic DNA. Proc Natl Acad Sci USA 2004;101:17765-17770.

27. Selzer RR, Richmond TA, Pofahl NJ, Green RD, et al. Analysis of chromosome breakpoints in neuroblastoma at sub-kilobase resolution using fine-tiling oligonucleotide array CGH. Genes Chromosomes Cancer 2005;44:305-319.

28. Friedman JM, Baross A, Delaney AD, Ally A, et al. Oligonucleotide microarray analysis of genomic imbalance in children with mental retardation. Am J Hum Genet 2006;79:500-513.

29. Rauch A, Ruschendorf F, Huang J, Trautmann U, et al. Molecular karyotyping using an SNP array for genomewide genotyping. J Med Genet 2004;41:916-922.

30. Peiffer DA, Le JM, Steemers FJ, Chang W, et al. High-resolution genomic profiling of chromosomal aberrations using Infinium whole-genome genotyping. Genome Res 2006;16:1136-1148. 
31. Menten B, Maas N, Thienpont B, Buysse K, et al. Emerging patterns of cryptic chromosomal imbalances in patients with idiopathic mental retardation and multiple congenital anomalies: a new series of 140 patients and review of the literature. J Med Genet 2006;43:625-633.

32. Subramonia-Iyer S, Sanderson S, Sagoo G, Higgins J, et al. Array-based comparative genomic hybridization for investigating chromosomal abnormalities in patients with learning disability: systematic review meta-analysis of diagnostic and falsepositive yields. Genet Med 2007;9:74-79.

33. Lugtenberg D, de Brouwer AP, Kleefstra T, Oudakker AR, et al. Chromosomal copy number changes in patients with non-syndromic X linked mental retardation detected by array CGH. J Med Genet 2006;43:362-370.

34. Lugtenberg D, Yntema HG, Banning MJ, Oudakker AR, et al. ZNF674: A new Kruppel-associated box-containing zinc-finger gene involved in nonsyndromic X-linked mental retardation. Am J Hum Genet 2006;78:265-278.

35. Shoichet SA, Hoffmann K, Menzel C, Trautmann U, et al. Mutations in the ZNF41 gene are associated with cognitive deficits: identification of a new candidate for X-linked mental retardation. Am J Hum Genet 2003;73:1341-1354.

36. Kleefstra T, Yntema HG, Oudakker AR, Banning MJ, et al. Zinc finger 81 (ZNF81) mutations associated with X-linked mental retardation. J Med Genet 2004;41:394-399.

37. Van Esch H, Bauters M, Ignatius J, Jansen M, et al. Duplication of the MECP2 region is a frequent cause of severe mental retardation and progressive neurological symptoms in males. Am J Hum Genet 2005;77:442-453.

38. Meins M, Lehmann J, Gerresheim F, Herchenbach J, et al. Submicroscopic duplication in Xq28 causes increased expression of the MECP2 gene in a boy with severe mental retardation and features of Rett syndrome. J Med Genet 2005;42:e12.

39. Friez MJ, Jones JR, Clarkson K, Lubs H, et al. Recurrent infections, hypotonia, and mental retardation caused by duplication of MECP2 and adjacent region in Xq28. Pediatrics 2006;118:e1687-e1695.

40. del Gaudio D, Fang P, Scaglia F, Ward PA, et al. Increased MECP2 gene copy number as the result of genomic duplication in neurodevelopmentally delayed males. Genet Med 2006;8:784-792.

41. Luikenhuis S, Giacometti E, Beard CF, Jaenisch R. Expression of MeCP2 in postmitotic neurons rescues Rett syndrome in mice. Proc Natl Acad Sci USA 2004;101:6033-6038.

42. Froyen G, Bauters M, Boyle J, Van Esch H, et al. Loss of SLC38A5 and FTSJ1 at $\mathrm{Xp11.23}$ in three brothers with non-syndromic mental retardation due to a microdeletion in an unstable genomic region. Hum Genet 2007; 121: 539-547.

43. Van Esch H, Jansen A, Bauters M, Froyen G, et al. Encephalopathy and bilateral cataract in a boy with an interstitial deletion of Xp22 comprising the CDKL5 and NHS genes. Am J Med Genet A 2007;143:364-369.
44. Bonnet C, Gregoire MJ, Brochet K, Raffo E, et al. Pure de-novo $5 \mathrm{Mb}$ duplication at Xp11.22-p11.23 in a male: phenotypic and molecular characterization. JHum Genet 2006;51:815-821.

45. Shaw-Smith C, Redon R, Rickman L, Rio M, et al. Microarray based comparative genomic hybridisation (array-CGH) detects submicroscopic chromosomal deletions and duplications in patients with learning disability/mental retardation and dysmorphic features. J Med Genet 2004;41:241-248.

46. Iafrate AJ, Feuk L, Rivera MN, Listewnik ML, et al. Detection of large-scale variation in the human genome. Nat Genet 2004;36:949-951.

47. Jehee FS, Rosenberg C, Krepischi-Santos AC, Kok F, et al. An Xq22.3 duplication detected by comparative genomic hybridization microarray (Array-CGH) defines a new locus (FGS5) for FG syndrome. Am J Med Genet 2005;139:221-226.

48. Tyson C, Harvard C, Locker R, Friedman JM, et al. Submicroscopic deletions and duplications in individuals with intellectual disability detected by array-CGH. Am J Med Genet A 2005;139:173-185.

49. Solomon NM, Ross SA, Morgan T, Belsky JL, et al. Array comparative genomic hybridisation analysis of boys with $\mathrm{X}$ linked hypopituitarism identifies a $3.9 \mathrm{Mb}$ duplicated critical region at Xq27 containing SOX3. J Med Genet 2004;41: 669-678.

50. Mills RE, Luttig CT, Larkins CE, Beauchamp A, et al. An initial map of insertion and deletion (INDEL) variation in the human genome. Genome Res 2006;16:1182-1190.

51. Locke DP, Sharp AJ, McCarroll SA, McGrath SD, et al. Linkage disequilibrium and heritability of copy-number polymorphisms within duplicated regions of the human genome. Am J Hum Genet 2006;79:275-290.

52. Sharp AJ, Locke DP, McGrath SD, Cheng Z, et al. Segmental duplications and copy-number variation in the human genome. Am J Hum Genet 2005;77:78-88.

53. Tuzun E, Sharp AJ, Bailey JA, Kaul R, et al. Fine-scale structural variation of the human genome. Nat Genet 2005;37:727-732.

54. Redon R, Ishikawa S, Fitch KR, Feuk L, et al. Global variation in copy number in the human genome. Nature 2006;444:444-454.

55. McCarroll SA, Hadnott TN, Perry GH, Sabeti PC, et al. Common deletion polymorphisms in the human genome. Nat Genet 2006;38:86-92.

56. Simon-Sanchez J, Scholz S, Fung HC, Matarin M, et al. Genome-wide SNP assay reveals structural genomic variation, extended homozygosity and cell-line induced alterations in normal individuals. Hum Mol Genet 2007;16:1-14.

57. Schouten JP, McElgunn CJ, Waaijer R, Zwijnenburg D, et al. Relative quantification of 40 nucleic acid sequences by multiplex ligation-dependent probe amplification. Nucleic Acids Res 2002;30:e57. 